\title{
Artificial salivas
}

\section{Guy Carpenter ${ }^{1}$ (D)}

Received: 18 May 2018 / Accepted: 21 August 2018 / Published online: 23 October 2018

(c) The Author(s) 2018

Keywords Saliva $\cdot$ Xerostomia $\cdot$ Dry mouth $\cdot$ Carboxy-methyl cellulose .

Lubrication $\cdot$ Hydration

\section{Quick reference/description}

Mucosa is hydrated by the continuous flow of watery saliva over the mucosa and by the adhesion of mucins. This helps in keeping the mucosa moist and lubricated.

Artificial salivas mimic the viscous nature of saliva but lack the other physical properties of saliva $[1,2]$. To supplement any pre-existing saliva, artificial salivas should be complementary to any pre-existing saliva when used with dry mouth patients. Saliva has a lower surface tension than water which is created by the presence of surface active proteins. The low surface tension aids in spreading a thin film over the mucosa [3], but the low surface tension in artificial salivas, due to the presence of certain chemicals, overwhelms the natural surface tension of saliva which speeds evaporation.

\section{Indications}

Xerostomia or dry mouth, swallowing problems, taste disturbances or ulcerated mucosa.

\section{Materials/instruments}

Whole mouth saliva collectors, dry mouth visual analogue scales, Bother Index, Challacombe scale of clinical effects of xerostomia, rheometers were used.

Guy Carpenter

guy.carpenter@kcl.ac.uk

1 Salivary Research, King's College London Dental Institute, London, UK 


\section{Procedure}

Assessment of dry mouth should include subjective and objective symptoms. Salivary flow rate should be calculated (by measuring the volume over a set time), subjective signs by the Bother index or short questionnaire and objective symptoms by the Challacombe scale [4].

\section{Composition of artificial salivas}

To create viscosity, the main polymer in artificial salivas is either carboxymethylcellulose or xanthan gum. Low surface tension of artificial saliva is created by the addition of volatiles such as menthol. They also contain bioactives that are components extracted from natural sources (animals or plants) that have some of the bacteriostatic or antibacterial effects of natural saliva (Table 1).

\section{Physical properties of artificial and natural salivas}

Physical properties of saliva include:

- Viscosity

- Elasticity

- Surface tension

- Surface and bulk viscoelasticity

\section{Other possible sources for artificial saliva}

The other sources for artificial saliva currently being researched include:

- Post-transplantation of bio-engineered whole or mini-glands produced by laboratory biofabrication processes [5]

- Customized laboratory-based artificial saliva [6]

- Customized mouth splints designed to create a reservoir for longer delivery.

\section{Pitfalls and complications}

- Artificial salivas lack effectiveness.

- They do not mimic the elastic component and the pellicle-forming properties of real saliva.

- They have very low surface tension that destroys the properties of any existing saliva.

- Lack of suitable in vivo models to test artificial salivas 


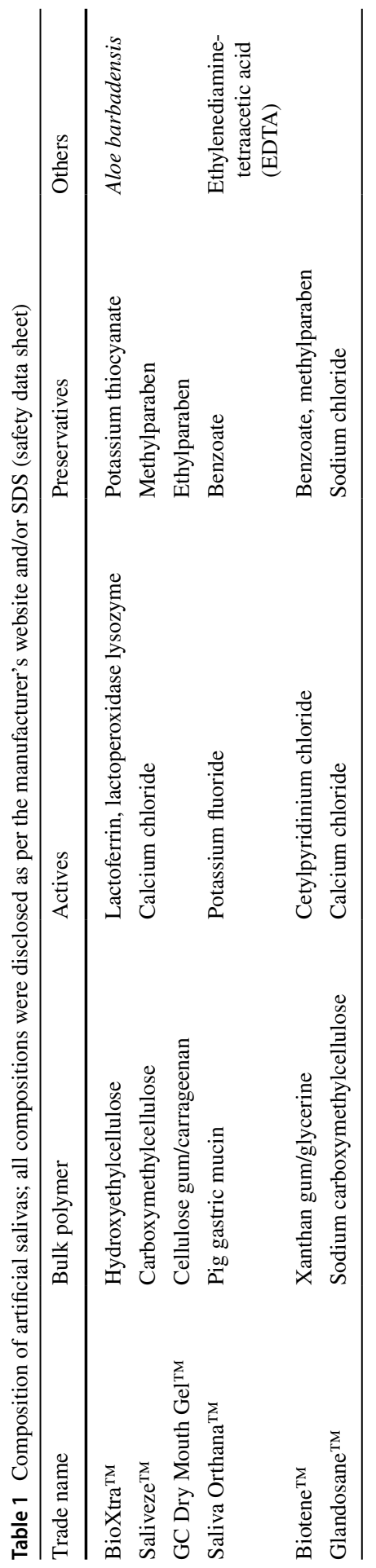


Open Access This article is distributed under the terms of the Creative Commons Attribution 4.0 International License (http://creativecommons.org/licenses/by/4.0/), which permits unrestricted use, distribution, and reproduction in any medium, provided you give appropriate credit to the original author(s) and the source, provide a link to the Creative Commons license, and indicate if changes were made.

\section{Further reading}

1. Carpenter G (ed) (2014) Dry mouth: a clinical guide on causes, effects and treatments. Springer, London. https://doi.org/10.1007/978-3-642-55154-3_11

2. Furness S, Worthington HV, Bryan G, Birchenough S, McMillan R (2011) Interventions for the management of drymouth: topical therapies. Cochrane Database Syst Rev 12:106

3. Klein J (2012) Polymers in living systems: from biological lubrication to tissue engineering and biomedical devices. Polym Adv Technol 23(4):729-735

4. Osailan S, Pramanik R, Shirodaria S, Challacombe SJ, Proctor GB (2011) Investigating the relationship between hyposalvation and mucosal wetness. Oral Dis 17(1):109-114

5. Lomaert I, Movahednia MM, Adine C, Ferreira JN (2017) Concise review: salivary gland regeneration: therapeutic approaches from stem cells to tissue organoids. Stem cells 35(1):97-105

6. Veeregowda DH, Kolbe A, van der Mei HC, Busscher HJ, Herrmann A, Sharma PK (2013) Recombinant superchargedpolypeptides restore and improve biolubrication. Adv Mater 25(25):3426-3431 